\title{
Investigation of the influence of impurities on the ring-opening polymerisation of L-Lactide from biogenous feedstock
}

\author{
Regina Itzinger ${ }^{1} \mathbb{D} \cdot$ Clemens Schwarzinger $^{1} \cdot$ Christian Paulik $^{1}$
}

Received: 28 July 2020 / Accepted: 31 October 2020 / Published online: 21 November 2020

(c) The Author(s) 2020

\begin{abstract}
In order to use a L-lactide monomer that is derived from fermentation processes it is necessary to understand, how the polymerisation process is influenced by impurities which derive from the production process. We have selected a group of likely contaminants and added them at various concentrations to the polymerisation of L-lactide using tin (II)-2-ethylhexanoate as catalyst and 2-methoxyethanol as initiator. The effect of impurities onto the global properties of the polymers such as glass transition temperature, melting point and molecular mass distribution were investigated and NMR and MALDI mass spectrometry were used to identify structural changes within the polymers. Thus, it could be shown that in reference experiments cyclic polymers and linear polymers with different starting groups are formed. Addition of ethanol and sodium carbonate showed the strongest influence on molecular masses as well as polymer structures, which could be elucidated by interpretation of the MALDI mass spectra and NMR data.
\end{abstract}

Keywords Poly (lactic acid) $\cdot$ Lactide $\cdot$ MALDI mass spectrometry $\cdot$ Biogenous feedstock

\section{Introduction}

One of the most heavily used commodity products worldwide are plastics. Plastic products are used in almost each and every part of our lives due to their properties and versatility. Polymers can be used in almost every shape, are light weight, their mechanical properties can be adjusted to a vast scale of requirements and polymers are at the very same time very cost efficient [1]. The production of plastics based on fossil feedstocks is still growing, however it is recently more and more questioned $[2,3]$. Therefore, the public's focus is moving towards so called bioplastics. Bioplastics can be divided into two groups, plastics originating from biogenous resources and biodegradable plastics irrespective of their origin. It is not mandatory that these specifications correlate $[4,5]$.

It is worth saying, that the production and usage of biopolymers is by far not an idea of our age. Already decades ago, biopolymers have been known but have

Regina Itzinger

regina.itzinger@jku.at

1 Institute for Chemical Technology of Organic Materials, Johannes Kepler University Linz, Altenbergerstraße 69, 4040 Linz, Austria been displaced by the cheaper and more versatile fossil based products $[6,7]$. Biopolymers that recently experience an increasing interest may be cellulose based polymers, starch and starch blends, poly( $\varepsilon$-caprolactone), poly(butylene succinate), poly(butylene adipate-co-terephthalate), poly(hydroxy alkanoate) and poly(lactic acid) [4]. Although, the properties of these biopolymers differ to the properties of fossil-based large volume polymers, the potential of biopolymers is huge. It is shown that the biodegradability provides a big advantage e.g. in medical applications. Products made from biodegradable plastics can be used in tissue engineering, for implants like screws, plates or anchors, as a fracture fixation or even for drug delivery systems. However, the usage of bioplastics is not limited to niche products in the medical area, but can also be expanded to fibre production and textile industry, the automotive sector or packaging, revealing a huge potential for the future market share [8-10].

The predicted volume of bioplastics has shown high growth rates for years. Market prospects foresee strongly growing production capacities, while the actual growth rate is lagging behind [11]. But still, the successive development of polymerisation plants, property modification of bioplastics and application adaption are leading to a rewarding market section that offers new 
perspectives [2]. Especially two kinds of biopolymers gain special attention: Poly(hydroxy alkanoate) PHA and poly(lactic acid) PLA tend to be among the most promising plastics, due to their versatile properties and broad application areas $[8,11,12]$.

There are two basic polymerisation techniques for the synthesis of PLA, polycondensation and ring-opening polymerisation ROP. Numerous publications examine the polymerisation possibilities of direct polycondensation. Ajioka et al. [13] showed in 1995 the applicability of Sn-powder as a catalyst in the direct polycondensation of lactic acid with reaction conditions of $9 \mathrm{~h}$ and $150{ }^{\circ} \mathrm{C}$ at reduced pressures leading to molecular masses up to $300000 \mathrm{~g} \mathrm{~mol}^{-1}$. Kim et al. [14] tested the impact of several Sn and Ti based catalysts via an azeotropic dehydration of lactic acid over 48 to $72 \mathrm{~h}$ leading to molecular masses of $33000 \mathrm{~g} \mathrm{~mol}^{-1}$, while Nagahata et al. [15] demonstrated that a microwave-assisted direct polycondensation of lactic acid is providing much faster reaction times with suitable molecular masses. The method of direct polycondensation requires quite high reaction temperatures, relatively long reaction times of several days and low pressures to sufficiently remove the condensate and therefore, gaining sufficient molecular masses. Therefore, the molecular masses obtained from direct polycondensation are low compared to ROP. Increasing focus is brought to the synthesis of PLA copolymers from direct polycondensation [16-18].

The more promising polymerisation technique for the synthesis of poly(lactic acid) is the ring-opening polymerisation. The ROP was already studied in 1959 by Kleine et al. [19] who were using $\mathrm{Zn}$ and $\mathrm{PbO}$ catalysts in a solution and solvent free polymerisation of lactide. Fischer et al. [20] enhanced the ROP investigation by means of $\mathrm{SnCl}_{4}$ as a catalyst. The polymerisation reaction was conducted in toluene, with reaction times of $20 \mathrm{~h}$ leading to promising molecular masses of $80000-100000 \mathrm{~g} \mathrm{~mol}^{-1}$. New catalyst systems are under investigation in recent times. For instance, Myers et al. [21] conducted a metal free approach on ROP of lactides using nucleophilic phosphines as transesterification catalysts. Lohmeijer et. al [22] are investigating guanidine and amidine catalyst systems that show high selectiveness and seem to be well suited for block-copolymers. Still, one of the most common catalyst systems used is Tin (II)-2-ethylhexanoate $\mathrm{Sn}(\mathrm{Oct})_{2}$ [23-26]. Due to the fact of its FDA approval for low toxicity it is a wide spread catalyst system which produces polymers with high molecular masses, proper yields and reasonable stereoregularity from various lactides and lactones [27, 28]. Karidi et al. [29] show that with simple variations of the initiator used in combination with $\mathrm{Sn}(\mathrm{Oct})_{2}$, branched polymers of all shapes can be produced. Furthermore, cyclic PLA is produced with the combination of $\mathrm{Sn}(\mathrm{Oct})_{2}$ and new initiators by Kricheldorf et al. [27] with molecular masses up to $170000 \mathrm{~g} \mathrm{~mol}^{-1}$. Ring-opening polymerisation is a promising technique of producing high molecular mass PLA which is underlined by the predominant amount of research in this field. New trends in PLA synthesis tend to grow in the direction of ring-expansion polymerisation REP, due to advantages in the degradation behaviour of cyclic polymers in comparison to linear polymers [27, 30, 31].

The synthesis route of PLA via ROP is in general leading to polymers with a higher molecular mass than via direct polycondensation, respectively. Therefore, the lactide needs to be of special polymeric grade quality, which purity exceeds the requirements for the food industry [32]. This grade is obtained by the dimerisation of lactic acid and extensive purification steps in lactic acid downstream processing [33]. This downstream processing from the fermentation broth is a complex task, which requires high time and energy consumption $[34,35]$. Still the production of lactic acid from fermentation is the most favourable pathway, since racemic pure lactic acid is obtained by the microorganisms utilised [36]. As the fermentation process has to fulfil special conditions for the microorganism's metabolism, the fermentation broth is a highly complex system with a large number of substances that may be present in the product and therefore may also intervene in the polymerisation process $[32$, 37-39].

The objective of this work was to investigate the impact on the PLA polymerisation process triggered by unwanted substances present in the monomer. These unwanted substances may originate from the fermentation broth or the downstream process of lactic acid. This means that nutritional substances for the microorganisms, metabolic by-products, filtration auxiliars and the like may act as a contaminant. Therefore, a reference experiment with high monomer purity is established, serving as basis for experiments with doped monomers. The impurities chosen for this study were selected in accordance to literature [32, 34-39].

\section{Materials \& methods}

L-lactide (purity, 98\%) and 2-methoxyethanol (purity, 99,8\%) were purchased from Sigma Aldrich. For further purification L-lactide was recrystallised in 2-propanol, dried in vacuo and stored under inert atmosphere. Tin (II)-2-ethylhexanoate (purity, technical grade) was purchased from Alfa Aesar. Ethanol (purity, absolute) and toluene (purity, pa) were purchased from VWR. Toluene was distilled over Na for further purification. 
$\mathrm{CaCO}_{3}$ (purity, 98\%), L(+)-aspartic acid (purity, 98+\%) and $\mathrm{L}(+)$-glutamic acid (purity, 99,2\%) were purchased from Acros Organics. $\mathrm{CaSO}_{4}$ (purity, $99 \%$ ), $\mathrm{Na}_{2} \mathrm{SO}_{4}$ (purity, pa) and $\mathrm{D}(+)$-glucose (purity, bio-grade) were purchased from Merck. $\mathrm{D}(+)$-sucrose (purity, 99,5\%) was purchased from Roth. All other solvents were of reagent grade. If not stated otherwise, all reagents and solvents were used without further purification.

Recrystallised L-lactide was polymerised by the use of Schlenk technique. $1 \mathrm{~g}$ of L-lactide was weighed in the glovebox, sealed in a vial and transferred to the prepared round bottom flask. The monomer was added to the reaction vessel with counterflow of inert gas and purged for several minutes. For initiating the ring-opening polymerisation $0.25 \mathrm{~mL}$ catalyst solution, (tin (II)2-ethylhexanoate, $0.2 \mathrm{~mol} \mathrm{~L}^{-1}$ in toluene, $0.05 \mathrm{mmol}$ ), and $0.1 \mathrm{~mL}$ initiator solution (2-methoxyethanol ME, $0.12 \mathrm{~mol} \mathrm{~L}^{-1}$ in toluene, $0.012 \mathrm{mmol}$ ) were added to the L-lactide via a rubber stopper using syringes purged with inert gas. The reaction mixture was stirred and kept at $180{ }^{\circ} \mathrm{C}$ for $1 \mathrm{~h}$ while solidification occurred. For quenching, the reaction was cooled for several minutes, $5 \mathrm{~mL}$ of chloroform were added via the rubber stopper and the reaction mixture was kept boiling under reflux until the formed polymer was fully dissolved. The polymer solution was cooled to room temperature (RT) and the polymer was precipitated by the dropwise addition of $15 \mathrm{~mL}$ methanol. The precipitated polymer was vacuum filtrated, washed several times with methanol and dried in a vacuum compartment dryer at $40{ }^{\circ} \mathrm{C}$.

For the study of the influence of impurities on the polymerisation of L-lactide the monomer was doped with different amounts of possible contaminants that may originate from the fermentation process of lactic acid or the down-stream processing previous to polymerisation. The monomer was doped with $0.1 \mathrm{w} \%$ (triple determination), $1.0 \mathrm{w} \%$ and $1.5 \mathrm{w} \%$ respectively. The polymerisation processes were conducted analogous to the reference experiments. For the contamination with ethanol, solutions of $0.21 \mathrm{~mol} \mathrm{~L}^{-1}$ and $2.14 \mathrm{~mol} \mathrm{~L}^{-1}$ in toluene were prepared. The addition of $0.1 \mathrm{~mL}$ and $0.15 \mathrm{~mL}$ of these solutions account for the addition of $0.1 \mathrm{w} \%, 1.0 \mathrm{w} \%$ and $1.5 \mathrm{w} \%$, respectively.

Differential scanning calorimetry DSC results were obtained using a Mettler Toledo DSC $3+$. The experiments were conducted in a Heat-Cool-Heat cycle evaluating the second heating cycle for the investigation of the PLA samples. The measurements were performed from $-40{ }^{\circ} \mathrm{C}$ to $200{ }^{\circ} \mathrm{C}$ with a heating rate of $10 \mathrm{~K} \mathrm{~min}^{-1}$, with a 3-min isothermal state before and in-between the dynamic sections, at the respective temperature. The nitrogen gas flow was $20 \mathrm{~mL} \mathrm{~min}^{-1}$.
Size exclusion chromatography SEC was conducted using an Agilent 1200 HPLC equipped with Phenomenex columns, a diode array detector DAD $(254 \mathrm{~nm})$ and an evaporative light scattering detector. The polymer samples were dissolved in $\mathrm{CHCl}_{3}$ at a concentration of approx. $6 \mathrm{mg} \mathrm{mL}^{-1}$. Each sample was doped with $0.5 \mu \mathrm{L}$ toluene / $\mathrm{mL}$ solvent used as an internal standard. The separation took place on a Phenomenex Guard column (SecurityGuard standard), and a series of Phenogel columns (Phenogel $5 \mu \mathrm{m} \mathrm{10E3} \mathrm{\AA ,} 300 \times 4.6 \mathrm{~mm}$; Phenogel

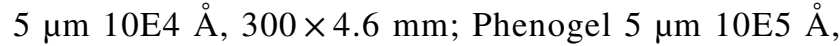
$300 \times 4.6 \mathrm{~mm}$ ). Analyses were carried out in $\mathrm{CHCl}_{3}$ at $40{ }^{\circ} \mathrm{C}$ with a flow rate of $0.35 \mathrm{~mL} \mathrm{~min}{ }^{-1}$ and an injection volume of $10 \mu \mathrm{L}$.

Mass spectra were recorded on a Bruker Autoflex III in reflectron mode. The samples were dissolved in chloroform $\left(10 \mathrm{mg} \mathrm{mL}^{-1}\right)$, mixed with trans-2-[4tert-butylphenyl-2-methyl-2-propylidene] malonitrile (DCTB; $10 \mathrm{mg} \mathrm{mL}^{-1}$ in chloroform) used as matrix and sodium trifluoroacetate $\left(1 \mathrm{mg} \mathrm{mL}^{-1}\right.$ in THF) to enable sodium adduct formation in the ratio matrix:sample:salt $=100: 10: 1.1 \mu \mathrm{L}$ of this solution was applied onto the MALDI target.

${ }^{1} \mathrm{H}-\mathrm{NMR}$ and HSQC spectra were recorded on a Bruker Avance III $700 \mathrm{MHz}$ spectrometer. Samples were dissolved in $\mathrm{CDCl}_{3}$ with a concentration of approximately $1.2 \mathrm{mg} \mathrm{mL}^{-1}$.

\section{Results \& discussion}

\section{Polymerisation}

For the standard value assessment of the poly (lactic acid) synthesis the recrystallised L-lactide was polymerised as stated in the section above. In the following these experiments are conducted as reference experiments. The experiments were performed repeatedly throughout the investigation. During the reaction time the bulk in the round-bottom flask became highly viscous and solid at the end of the polymerisation. A colour change of the reaction mixture from clear to slightly beige could be observed within the reference experiments. After precipitation and filtration, a white powder was obtained.

For the investigation of the impact of possible impurities the following substances were chosen: $\mathrm{L}(+)$-aspartic acid, $\mathrm{L}(+)$-glutamic acid, $\mathrm{CaSO}_{4}, \mathrm{CaCO}_{3}, \mathrm{D}(+)$-sucrose, $\mathrm{D}(+)$-glucose, ethanol, and $\mathrm{Na}_{2} \mathrm{CO}_{3}$. The syntheses were performed analogous to the standard procedure. The experiments containing the stated quantities of $\mathrm{L}(+)$-aspartic acid, $\mathrm{L}(+)$-glutamic acid, $\mathrm{CaSO}_{4}$, and $\mathrm{CaCO}_{3}$ all showed similar reaction behaviour, leading 
to a solid product in the reaction flask. Although the reaction bulks showed light yellow and opaque appearances, white to off-white products were isolated. Also the experiments regarding $\mathrm{D}(+)$-sucrose led to a solid reaction bulk within $1 \mathrm{~h}$. It had a similar yellowish and cloudy appearance, but small dark chunks could be identified. When doping the reference experiment with ethanol also a yellowish and cloudy reaction mixture was obtained. However, the mixture showed a reduced viscosity. Within $1 \mathrm{~h}$ reaction time a gel-like product was formed, which was introduced to the workup, leading to an off-white powder of PLA. The syntheses of PLA with $\mathrm{D}(+)$-glucose as a contaminant also showed a significantly reduced viscosity of the reaction bulk. Additionally, the colour of the reaction mixture turned dark brown to black, giving a beige PLA product. The experiments regarding contamination with $\mathrm{Na}_{2} \mathrm{CO}_{3}$ showed various differences among the concentration variation. Experiments containing $0.1 \mathrm{w} \% \mathrm{Na}_{2} \mathrm{CO}_{3}$ showed reaction properties alike the reference experiments, with light yellow colouring of the bulk and a white powdery product. When $1.0 \mathrm{w} \%$ of $\mathrm{Na}_{2} \mathrm{CO}_{3}$ was present in the reaction mixture its colour changed to yellow. Sticking to the workup routine no solid polymer could be precipitated. Therefore, additional methanol was added until a precipitate was formed. After filtration an additional oil-like phase was obtained, which was also dried and found to contain PLA. Both samples obtained were investigated. At the presence of $1.5 \mathrm{w} \% \mathrm{Na}_{2} \mathrm{CO}_{3}$ no solid product could be precipitated during the workup. As a consequence, the methanolic solution was removed by the use of a rotary evaporator, leaving a sticky, brown to yellowish paste as a product.

\section{Differential scanning calorimetry}

Thermal investigations of the reference experiments indicate an average glass transition temperature $T_{\mathrm{g}}$ of $53{ }^{\circ} \mathrm{C} \pm 3{ }^{\circ} \mathrm{C}$ and an average melting point $T_{\mathrm{m}}$ of
Table 1 Thermal properties $\mathrm{T}_{\mathrm{g}}$ and $\mathrm{T}_{\mathrm{m}}$, mean molecular masses $M_{n}$ and $M_{w}$, polydispersity $Ð$ and calculated influences of polymerisation products synthesised. Values stated with $0.1 \mathrm{w} \%$ impurity are mean values from 3 repeated experiments. Values stated as reference are mean values from 18 repeated experiments

\begin{tabular}{|c|c|c|c|c|c|c|c|c|}
\hline & Impurity amount & $T_{\mathrm{g}}$ & $T_{\mathrm{m}}$ & Influence on $T_{\mathrm{m}}$ & $M_{\mathrm{n}}$ & $M_{\mathrm{w}}$ & $Ð$ & $\begin{array}{l}\text { Influ- } \\
\text { ence on } \\
M_{\mathrm{w}}\end{array}$ \\
\hline & $/ \mathrm{w} \%$ & $1{ }^{\circ} \mathrm{C}$ & $1{ }^{\circ} \mathrm{C}$ & $1 \%$ & $/ \mathrm{g} \mathrm{mol}^{-1}$ & $/ \mathrm{g} \mathrm{mol}^{-1}$ & - & $1 \%$ \\
\hline Reference & - & 54 & 164 & - & 20100 & 30900 & 1.54 & - \\
\hline \multirow[t]{3}{*}{$\mathrm{L}(+)$-Aspartic acid } & 0.1 & 58 & 166 & 1,3 & 21900 & 34700 & 1.59 & 12 \\
\hline & 1.0 & 52 & 164 & -0.2 & 19400 & 30300 & 1.56 & -2 \\
\hline & 1.5 & 53 & 164 & -0.3 & 19000 & 29900 & 1.57 & -3 \\
\hline \multirow[t]{3}{*}{ L(+)-Glutamic acid } & 0.1 & 56 & 165 & 0.6 & 18500 & 29000 & 1.56 & -6 \\
\hline & 1.0 & 49 & 163 & -1.0 & 10000 & 14800 & 1.46 & -52 \\
\hline & 1.5 & 49 & 159 & -3.0 & 8400 & 11500 & 1.36 & -63 \\
\hline \multirow[t]{4}{*}{$\mathrm{Na}_{2} \mathrm{CO}_{3}$} & 0.1 & 55 & 163 & -0.6 & 19300 & 30700 & 1.59 & -1 \\
\hline & 1.0 & 51 & - & - & 17800 & 22400 & 1.26 & -45 \\
\hline & 1.0 & 46 & - & - & 13100 & 16900 & 1.29 & -28 \\
\hline & 1.5 & 26 & - & - & 3400 & 4000 & 1.15 & -87 \\
\hline \multirow[t]{3}{*}{$\mathrm{D}(+)$-Glucose } & 0.1 & 50 & 163 & -0.9 & 18700 & 30600 & 1.63 & -1 \\
\hline & 1.0 & 49 & 160 & -2.3 & 10000 & 14600 & 1.47 & -53 \\
\hline & 1.5 & 47 & 157 & -4.5 & 9800 & 14500 & 1.47 & -53 \\
\hline \multirow[t]{3}{*}{$\mathrm{D}(+)$-Sucrose } & 0.1 & 52 & 162 & -1.2 & 17400 & 26700 & 1.53 & -14 \\
\hline & 1.0 & 49 & 160 & -2.5 & 11400 & 17800 & 1.56 & -42 \\
\hline & 1.5 & 50 & 161 & -1.9 & 11300 & 17000 & 1.50 & -45 \\
\hline \multirow[t]{3}{*}{$\mathrm{CaSO}_{4}$} & 0.1 & 51 & 162 & -1.2 & 18800 & 30700 & 1.64 & -1 \\
\hline & 1.0 & 51 & 162 & -1.4 & 11200 & 17100 & 1.53 & -45 \\
\hline & 1.5 & 50 & 161 & -2.3 & 9700 & 13800 & 1.42 & -56 \\
\hline \multirow[t]{3}{*}{ Ethanol } & 0.1 & 48 & 165 & 0.3 & 19300 & 29200 & 1.51 & -5 \\
\hline & 1.0 & 46 & 156 & -4.8 & 9500 & 12400 & 1.31 & -60 \\
\hline & 1.5 & 42 & 154 & -6.4 & 7900 & 9800 & 1.24 & -68 \\
\hline \multirow[t]{3}{*}{$\mathrm{CaCO}_{3}$} & 0.1 & 52 & 163 & -0.5 & 21700 & 34600 & 1.59 & 12 \\
\hline & 1.0 & 51 & 162 & -1.6 & 18400 & 27100 & 1.48 & -12 \\
\hline & 1.5 & 50 & 162 & -1.6 & 16100 & 23700 & 1.47 & -23 \\
\hline
\end{tabular}


$163.6{ }^{\circ} \mathrm{C} \pm 1.9{ }^{\circ} \mathrm{C}$, respectively. Thermal properties of samples prepared with $\mathrm{D}(+)$-sucrose, $\mathrm{CaSO}_{4}$, and $\mathrm{CaCO}_{3}$ indicate only a minor influence. The glass transition temperatures and the melting points of these samples at lower impurity content are within the range of standard deviation of the reference experiments. Increasing impurity contents are leading to a decrease in $T_{\mathrm{g}}$ and $T_{\mathrm{m}}$ of 2-4 ${ }^{\circ} \mathrm{C}$. The presence of $\mathrm{D}(+)$-sucrose, $\mathrm{CaSO}_{4}$, and $\mathrm{CaCO}_{3}$ results in a minor impact on the produced polymer denoting that these impurities have low relevance on the thermal polymer properties. Enhanced influence on the $T_{\mathrm{g}}$ and $T_{\mathrm{m}}$ is seen from experiments doped with L-glutamic acid and $\mathrm{D}(+)$-glucose. At an impurity content of $0.1 \mathrm{w} \% T_{\mathrm{g}}$ and $T_{\mathrm{m}}$ show less dependence, but with increasing impurity content $T_{\mathrm{g}}$ and $T_{\mathrm{m}}$ of the samples drop distinctly by $5-7{ }^{\circ} \mathrm{C}$. Further leverage can be identified by the addition of ethanol. The thermal properties are affected strongly by the presence of ethanol in the reaction mixture. The glass transition temperature drops by $12{ }^{\circ} \mathrm{C}$ and the melting point is decreased by $10{ }^{\circ} \mathrm{C}$. The investigations concerning $\mathrm{Na}_{2} \mathrm{CO}_{3}$ do not show an impact on the thermal properties at the amount of $0.1 \mathrm{w} \%$, but with increasing impurity content the glass transition temperature dropped by $28^{\circ} \mathrm{C}$. A melting point could not be detected for samples with $1.0 \mathrm{w} \%$ or $1.5 \mathrm{w} \%$ $\mathrm{Na}_{2} \mathrm{CO}_{3}$ respectively. The DSC analysis reveals that $\mathrm{Na}_{2} \mathrm{CO}_{3}$ is dramatically intervening the polymerisation of L-lactide. No crystalline regions within the synthesised macromolecules are built. The analyses of samples with $\mathrm{L}(+)$-aspartic acid show a different behaviour. $T_{\mathrm{g}}$ and $T_{\mathrm{m}}$ both show an increase at an impurity content of $0.1 \mathrm{w} \%$. Rising amounts of $\mathrm{L}(+)$-aspartic acid depress the thermal properties back into the standard deviation range of the reference experiments. In Table 1 the values for $T_{\mathrm{g}}$ and $T_{\mathrm{m}}$ are given.

The effects of impurities on the melting points are depicted in Fig. 1 in the form of deviation in \% relative to the reference experiments. The zero line determines the average melting point of the reference experiments, the grey area describes the standard deviation within the reference experiments.

In Fig. 2 exemplarily the thermal behaviours of $\mathrm{CaCO}_{3}$, $\mathrm{D}(+)$-glucose, ethanol, and $\mathrm{L}(+)$-aspartic acid are denoted.

All synthesised and investigated polymers show the presence of an exothermic peak in the heating curve. This peak indicates the effect of cold crystallisation, which means that the cooling process was too quick, the crystallisation of the PLA was not sufficient and therefore a crystallisation effect occurs when the polymeric chains become flexible. The cold crystallisation is visualised in Fig. 3, where the thermograms of a reference experiment and a $\mathrm{CaSO}_{4}$ doped experiment are given. The thermograms also indicate a difference for stronger contaminated samples, regarding the melting behaviour. With increasing impurity content, an enhanced double melting peak is observed. This holds true for experiments doped with $\mathrm{CaCO}_{3}$, ethanol, $\mathrm{CaSO}_{4}$, $\mathrm{D}(+)$-sucrose, $\mathrm{D}(+)$-glucose, and $\mathrm{L}(+)$-glutamic acid. It leads to the assumption that although $\mathrm{CaCO}_{3}, \mathrm{CaSO}_{4}$, and $\mathrm{D}(+)$-sucrose only have a minor impact on the melting point, there might be an influence on the lamella formation within the crystals [40].

\section{Size exclusion chromatography}

The investigations of the reference experiments via size exclusion chromatography indicate a mean number average molecular mass $M_{\mathrm{n}}$ of $20100 \mathrm{~g} \mathrm{~mol}^{-1} \pm 1300 \mathrm{~g} \mathrm{~mol}^{-1}$ and a mean weight average molecular mass $M_{\mathrm{w}}$ of $30900 \mathrm{~g} \mathrm{~mol}^{-1} \pm 2800 \mathrm{~g} \mathrm{~mol}^{-1}$, respectively. The investigations of PLA samples with contaminants showed an influence on both $M_{\mathrm{n}}$ and $M_{\mathrm{w}}$ for all the chosen substances. The contamination with the substances at a level of $0.1 \mathrm{w} \%$ led to the result that there is no significant impact on the molecular mass, except for $\mathrm{L}(+)$-aspartic acid and $\mathrm{CaCO}_{3}$ which cause the $M_{\mathrm{n}}$ and $M_{\mathrm{w}}$ to increase. The changes of $M_{\mathrm{w}}$ at a contamination level of $0.1 \mathrm{w} \%$ vary within the standard deviation range of the reference experiments. Therefore, a contamination at this level doesn't seem to cause problems in the polymer formation. Concerning the experiments with higher contamination levels, the interference of the chosen substances is demonstrated severely. The synthesised polymers

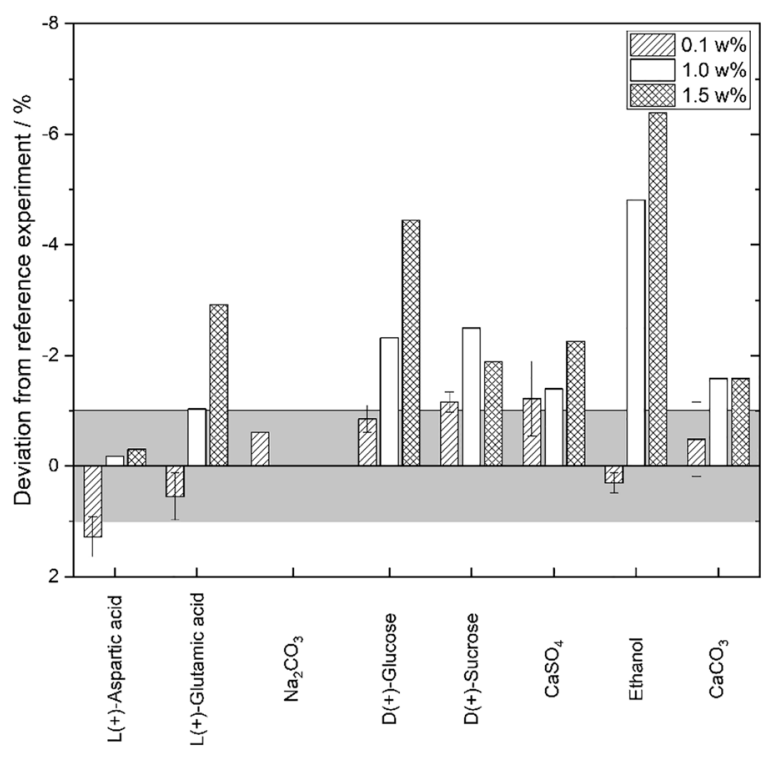

Fig. 1 Deviation of the melting point $T_{\mathrm{m}}$ in \% relatively to the reference experiments. For samples prepared with $1.0 \mathrm{w} \% \mathrm{Na}_{2} \mathrm{CO}_{3}$ and $1.5 \mathrm{w} \% \mathrm{Na}_{2} \mathrm{CO}_{3}$ no melting point could be measured 

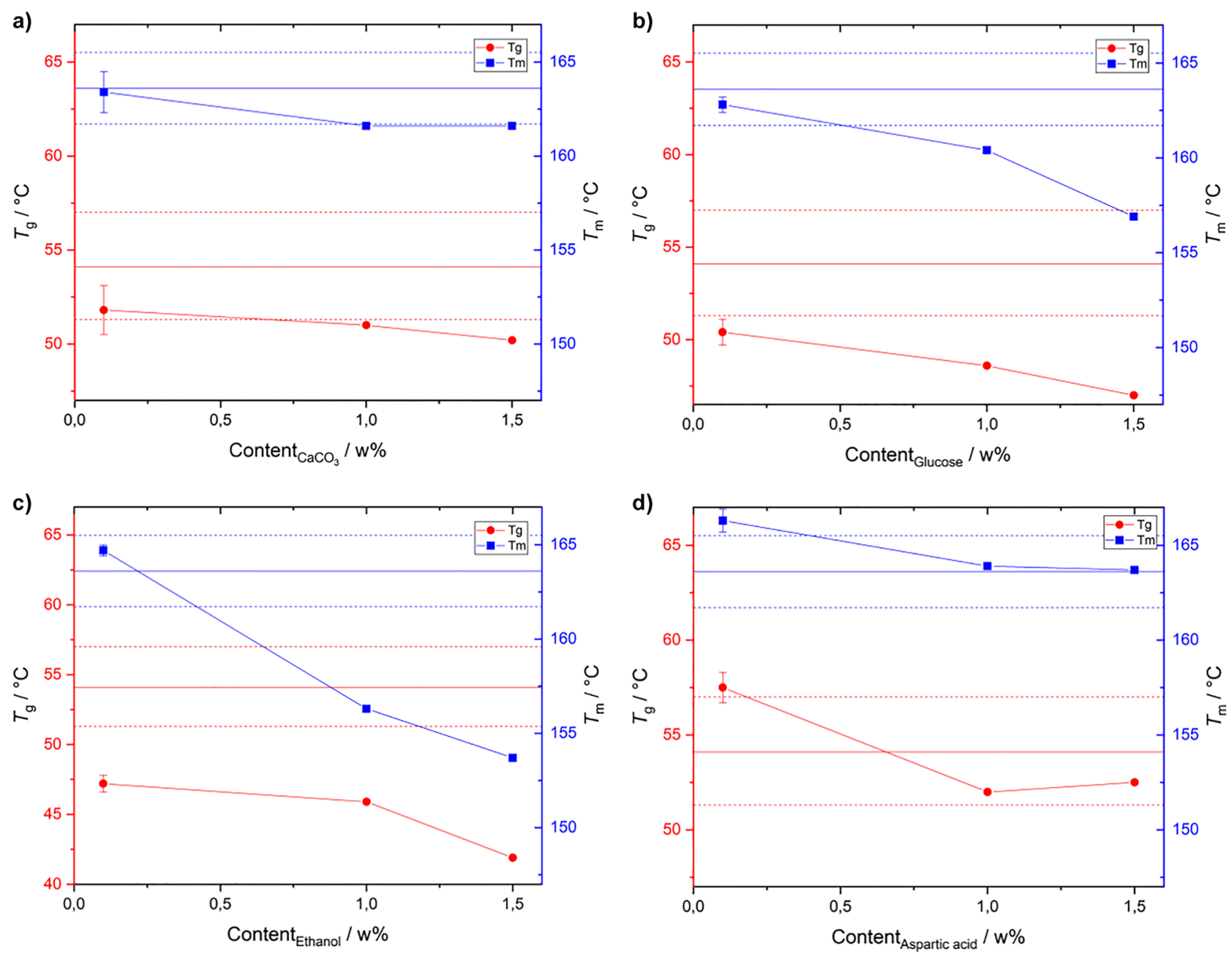

Fig. 2 Trend of glass transition temperature $T_{\mathrm{g}}$ and melting point $T_{\mathrm{m}}$ depending on the contamination value; a) $\mathrm{CaCO}$, b) $\mathrm{D}(+)$-glucose, c) ethanol, d) L(+)-aspartic acid

doped with $1.0 \mathrm{w} \%$ and $1.5 \mathrm{w} \% \mathrm{CaCO}_{3}$ suffered from a loss in the weight average molecular mass of up to $7500 \mathrm{Da}$. The consequences of an impurification on the $M_{\mathrm{w}}$ are even stronger for the monomer pollution with $\mathrm{L}(+)$-glutamic acid, $\mathrm{D}(+)$-glucose, $\mathrm{D}(+)$-sucrose, and $\mathrm{CaSO}_{4}$. All of these substances cause a loss in the $M_{\mathrm{w}}$ in the order of approximately 50 to $60 \%$, in this case yielding polymers of only $10000-17000 \mathrm{~g} \mathrm{~mol}^{-1}$. The high impact on the molecular masses is visualised in Fig. 4. In the presence of ethanol, the polymerisation is already highly affected at $1.0 \mathrm{w} \%$. As depicted in Fig. 5 the weight average molecular mass is only reaching a level of $12400 \mathrm{~g} \mathrm{~mol}^{-1}$ at $1.0 \mathrm{w} \%$ pollution and approx. $10000 \mathrm{~g} \mathrm{~mol}^{-1}$ at $1.5 \mathrm{w} \%$ pollution, respectively. This is a consequence of the fact that ethanol acts as an additional initiator just like 2-methoxyethanol and can therefore start the polymerisation. By calculating the theoretically achievable number average molecular mass $M_{\mathrm{n}}$, it can be identified that ethanol and 2-methoxyethanol are in competition with each other. When calculating the theoretical achievable molecular mass for the experiments doped with ethanol on the basis of mass conservation by considering the initiator/monomer ratio it can be seen, that the detected molecular masses exceed the theoretically achievable value by the factor of 2 to 3 . The calculation is performed with respect to the fact that 


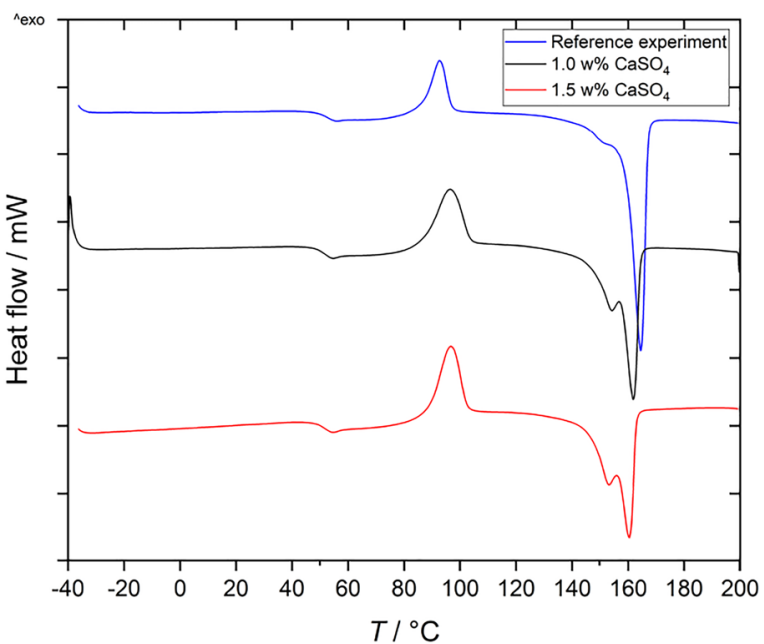

Fig. 3 Exemplarily thermogram of a PLA reference experiment and PLA contaminated with $1.0 \mathrm{w} \%$ and $1.5 \mathrm{w} \% \mathrm{CaSO}_{4}$

both methoxyethanol and ethanol can trigger a polymer chain growth. When $\mathrm{Na}_{2} \mathrm{CO}_{3}$ is present in the monomer a dramatic loss of the $M_{\mathrm{w}}$ is emerging in these experiments, revealing a product that can hardly be defined as a polymer, with a $M_{\mathrm{w}}$ of approximately $4000 \mathrm{~g} \mathrm{~mol}^{-1}$ at a contamination value of $1.5 \mathrm{w} \%$. The drastic interferences of possible contaminants from the fermentation broth in the polymer synthesis is depicted in Fig. 4. The deviation in \% relative to the reference experiments is given, where the influences are displayed in contrast to each other. Contrary to all other substances used as a contaminant in the L-lactide polymerisation, rising amounts of $\mathrm{L}(+)$-aspartic acid did not cause a significant decrease in the weight average molecular mass of PLA. In fact, a $0.1 \mathrm{w} \%$ content is causing an increase of the $M_{\mathrm{w}}$. The same is true for a $0.1 \mathrm{w} \%$ content of $\mathrm{CaCO}_{3}$ in the reaction mixture. In Fig. 4 this influence is shown, denoting that longer chain lengths result from the presence of $0.1 \mathrm{w} \% \mathrm{~L}(+)$-aspartic acid and $0.1 \mathrm{w} \% \mathrm{CaCO}_{3}$. The values determined are given in Table 1.

In Fig. 5 exemplarily the trends in the molecular masses of $\mathrm{CaCO}_{3}, \mathrm{D}(+)$-glucose, ethanol, and $\mathrm{L}(+)$-aspartic acid are denoted. In Fig. 6 exemplarily SEC curves of PLA samples are given. At a retention time of 31.5 min remaining L-lactide is detected. For the calculation of the molecular mass this area was excluded.
Fig. 4 Deviation of the weight average molecular mass $M_{\mathrm{w}}$ in $\%$ relatively to the reference experiments

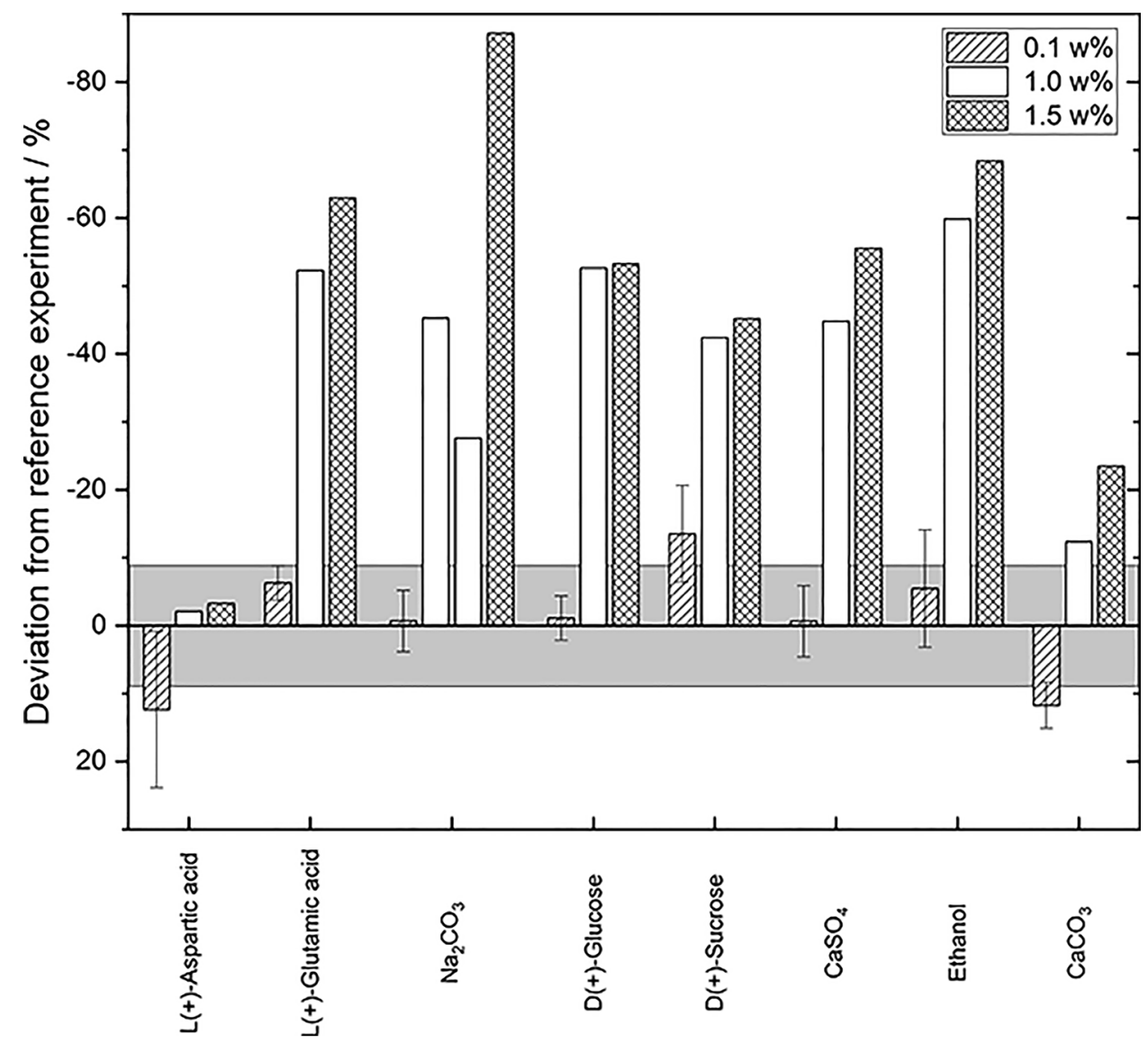



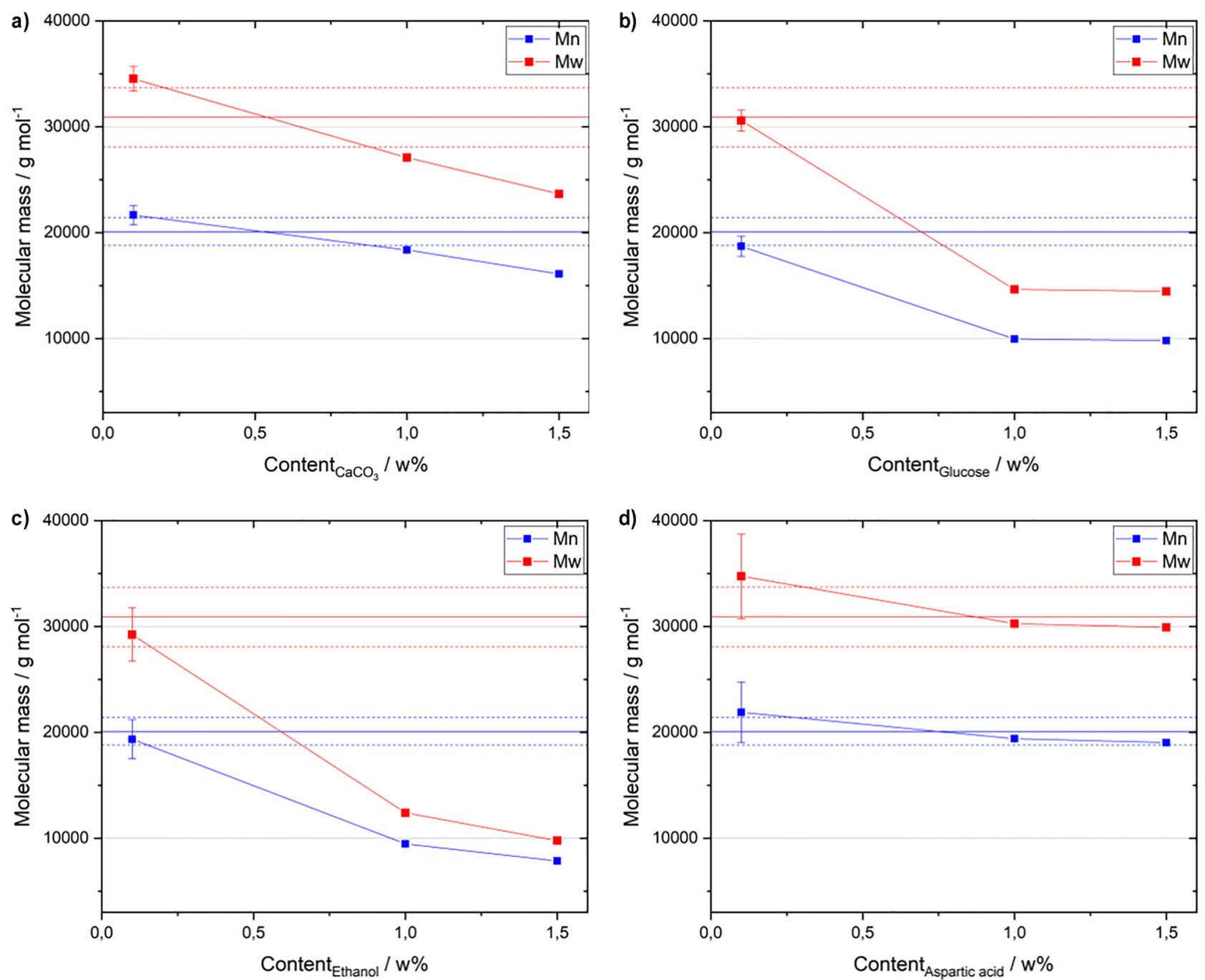

Fig. 5 Trend of number average molecular mass $M_{n}$ and weight average molecular mass $M_{w}$ depending on the contamination value; a) CaCO , b) $\mathrm{D}(+)$-glucose, c) ethanol, d) L(+)-aspartic acid

\section{MALDI mass spectrometry}

In contrast to NMR mass spectrometry gives an insight into the various molecular species present in the PLA polymer. Whereas cyclic PLA and linear structures cannot be distinguished by NMR, MALDI MS shows different polymer moieties due to the differences in their end groups as individual series [27, 30, 31].

Even if molecular mass distributions cannot be assessed for large PLAs with high dispersity, it is nevertheless possible to distinguish between smaller and larger molecular mass distributions (see Fig. 7). The analysis of the reference polymer initiated with methoxyethanol given in Fig. 8 shows clearly how complex the formation mechanism of the polymer is. Besides the linear polymer with a methoxyethyl starting group there are cyclic

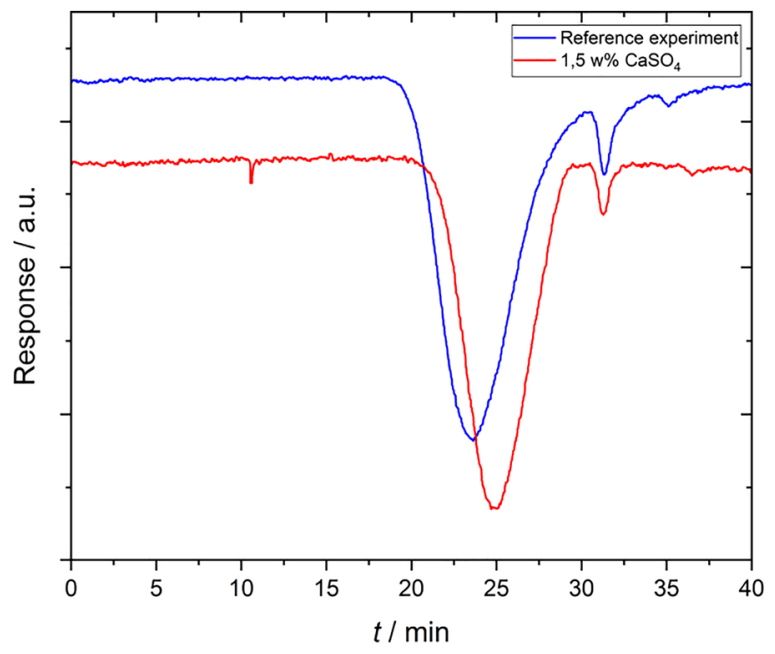

Fig. 6 Exemplarily illustration of SEC curves of a PLA reference experiment and PLA contaminated with $1.5 \mathrm{w} \% \mathrm{CaSO}_{4}$ 
Fig. 7 MALDI mass spectra of reference sample, sample with $1.5 \mathrm{w} \%$ ethanol, and $1.5 \mathrm{w} \%$ $\mathrm{Na}_{2} \mathrm{CO}_{3}$
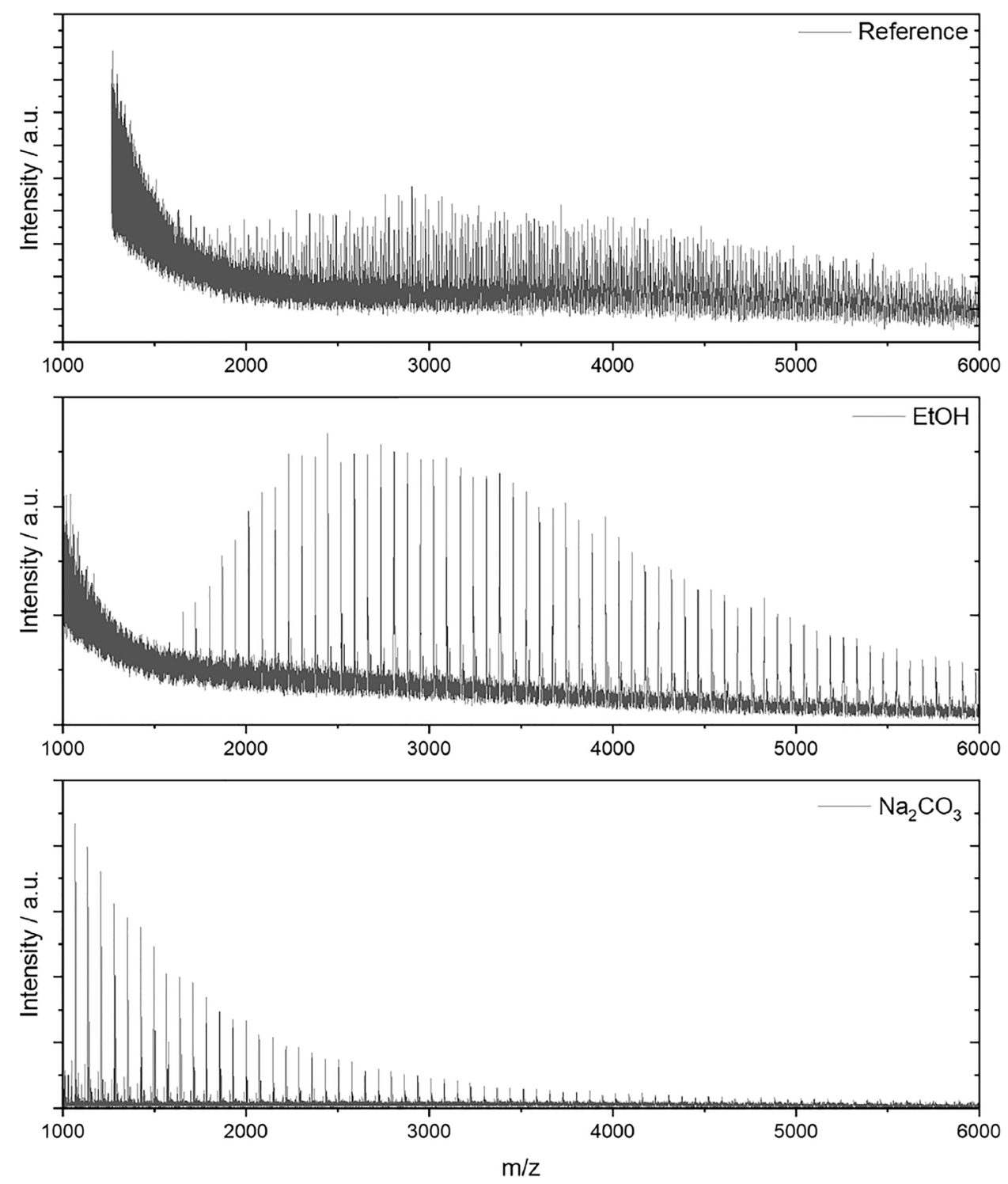

molecules and linear molecules with no starting group $\left(\mathrm{H}_{2} \mathrm{O}\right.$ induced $)$ and a methyl starting group. One series that differs from the cyclic species by $60 \mathrm{Da}$ was also found but could not be identified yet.

When ethanol is added it also acts as initiator for the polymerization and a series of molecules with ethyl starting groups is formed. Increasing the ethanol concentration thus leads to a dominance of this initiation mechanism and thus shorter polymer chains (see Fig. 8). When methoxyethanol is substituted with ethanol the same species can be found like in the reference experiment, only the moieties with methoxyethanol starting groups are missing.
The effect of $\mathrm{Na}_{2} \mathrm{CO}_{3}$ is also clearly visible in the mass spectrum. Only small polymer chains are found, which is in good agreement with NMR data; the moieties identified are methoxy initiated open chains, cyclic polymers, and due to the high alkalinity, the sodium salts of linear chains are also found. To a small extent also molecules ionized with potassium instead of sodium can be found, which is typical for ionization with alkali salts.

Addition of aspartic acid, however, did not produce any difference in the mass spectrum when compared to the reference experiment. Incorporation of aspartic acid into the polymer chain is not observed and it thus remains unclear, why higher molecular masses are obtained. 
Fig. 8 MALDI mass spectra of reference sample, sample with $1.5 \mathrm{w} \%$ ethanol, and 1.5 w\% $\mathrm{Na}_{2} \mathrm{CO}_{3}$; a) cyclic-PLA, b) ME-PLA-H, c) HO-PLA-H, d) Et-O-PLA-H, e) unknown, f) Me-O-PLA-H, g) HO-PLA-Na; Signals between series $\mathrm{c}$ and $\mathrm{d}$ are likely artefacts
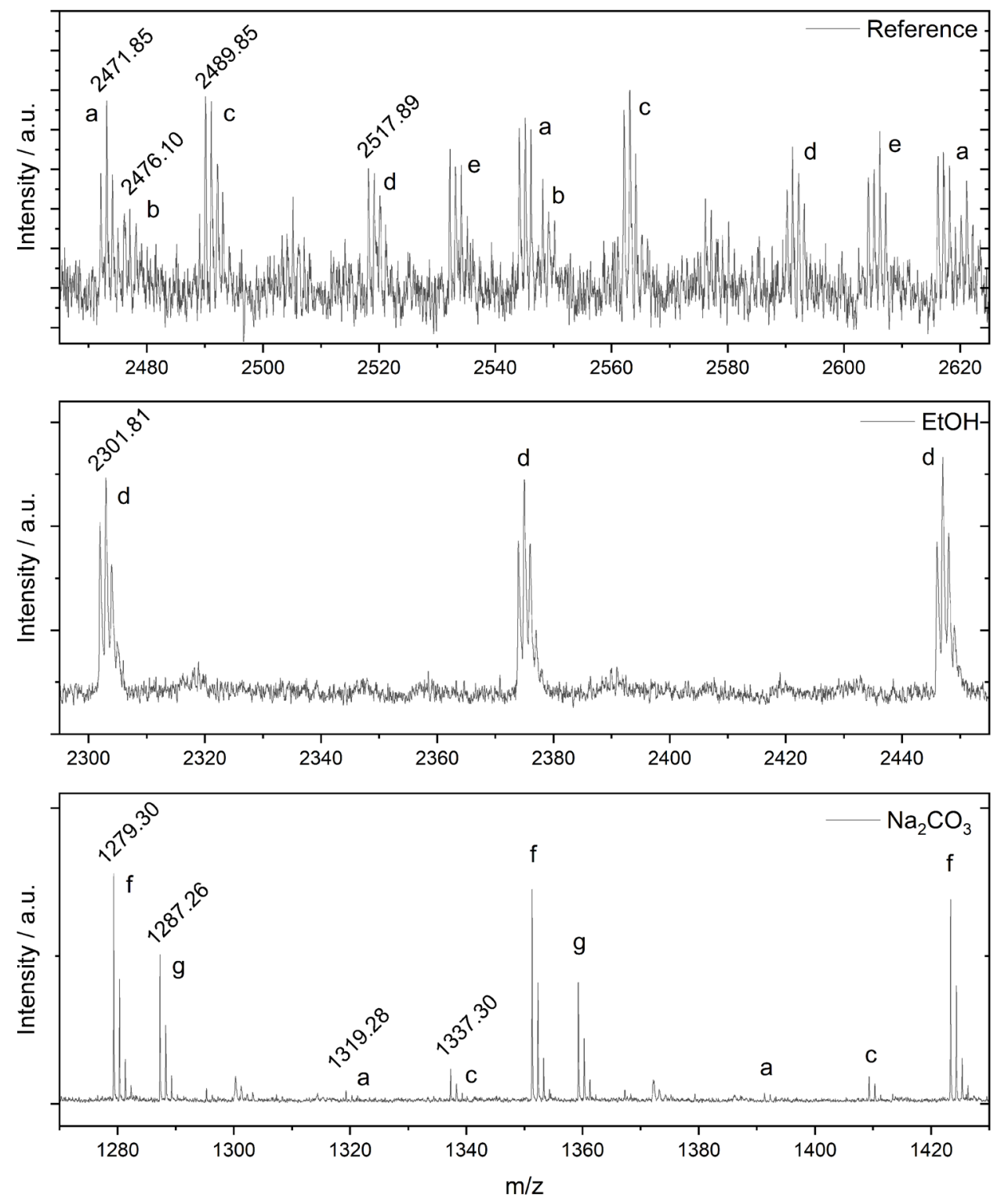

\section{NMR}

By investigation of the reference experiments the characteristic signals at $5.16 \mathrm{ppm}$ (quartet, methine group) and $1.57 \mathrm{ppm}$ (doublet, methyl group) of PLA could be found (see Fig. 9). Signals downfield shifted of both, the methine and the methyl group, can be determined to be caused by D-enantiomers and signals shifted upfield originate from shorter polymer chains, caused by the dispersity of the product [41]. Furthermore, methine and methyl end groups of the linear chains within the product are identified at $4.35 \mathrm{ppm}$ (quartet, methin end group) and $1.49 \mathrm{ppm}$ (doublet, methyl end group). Additionally, the signals from the methoxyethanol starting group can be identified at $4.19 \mathrm{ppm}\left(\mathrm{CH}_{3}-\mathrm{O}-\mathrm{CH}_{2}-\mathrm{CH}_{2^{-}}\right), 3.75 \mathrm{ppm}$ $\left(\mathrm{CH}_{3}-\mathrm{O}-\mathrm{CH}_{2}-\mathrm{CH}_{2}-\right)$ and $3.36 \mathrm{ppm}\left(\mathrm{CH}_{3}-\mathrm{O}-\mathrm{CH}_{2}-\mathrm{CH}_{2}-\right)$. The discrepancies of the relative signal areas within methoxyethanol originate from the large number of species in the product, as confirmed by MALDI-MS analyses. Supposedly, an overlapping of signals from different starting groups occurs.

As the MALDI-MS experiment already suggests, no differences in the PLA can be found when polymerisation with aspartic acid is conducted. The NMR spectrum is exactly alike to the reference PLA spectrum. 
Fig. 9 Relevant sections of ${ }^{1} \mathrm{H}-\mathrm{NMR}$ spectra of a) reference experiment, b) sample doped with $1.5 \mathrm{w} \%$ ethanol and c) sample doped with $1,5 \mathrm{w} \%$ $\mathrm{Na}_{2} \mathrm{CO}_{3}$
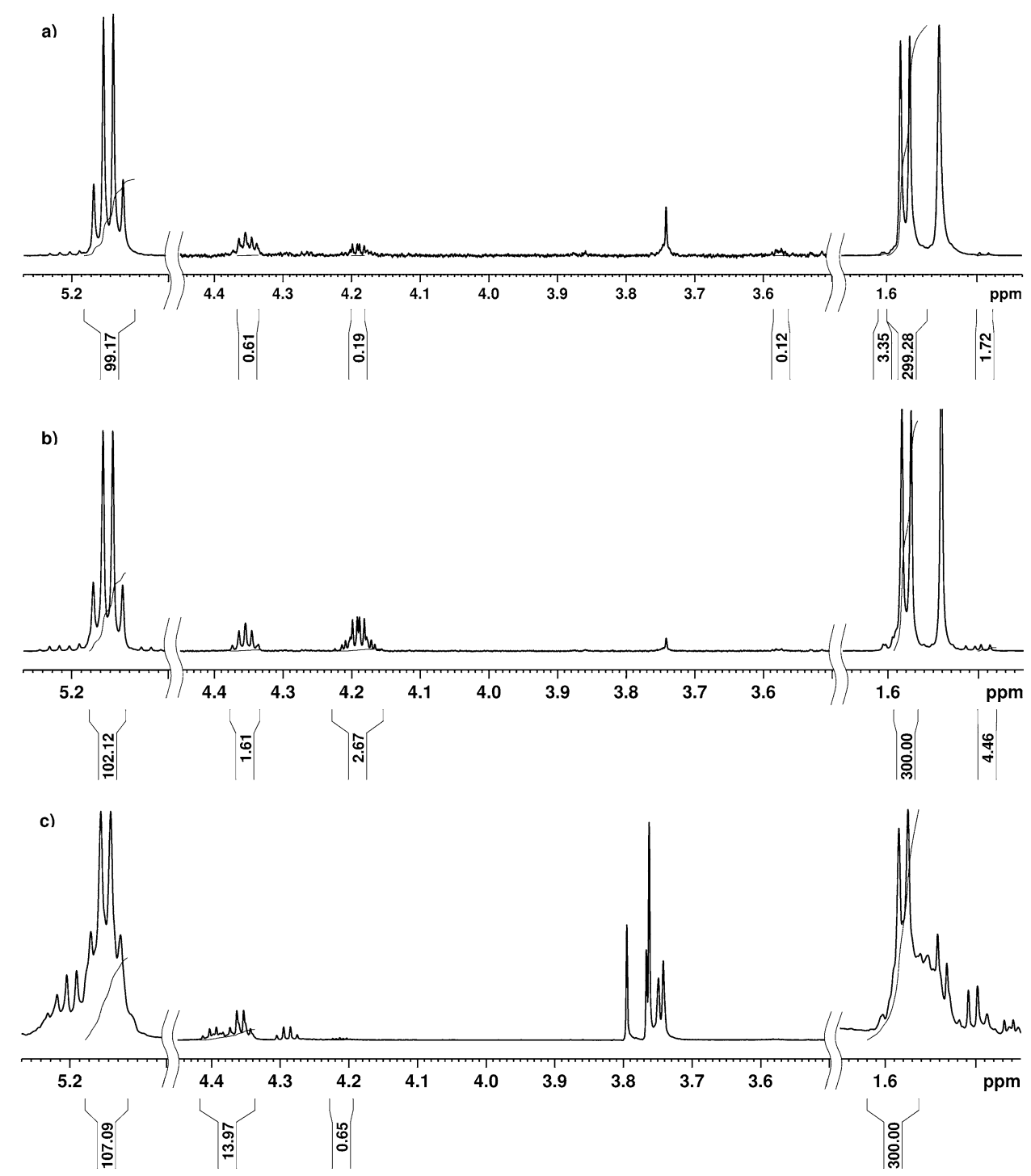

When ethanol is added to the reaction it acts as an additional initiator and these end groups were identified at $4.19 \mathrm{ppm}$ (multiplet, $\mathrm{CH}_{3}-\mathrm{CH}_{2}-\mathrm{O}-$ ) and $1.26 \mathrm{ppm}$ (triplet, $\mathrm{CH}_{3}-\mathrm{CH}_{2}-\mathrm{O}-$ ), which was also confirmed by the HSQC spectrum and was further supported by the peak integral ratios. A calculation of the molecular mass for the experiment with $1.5 \mathrm{w} \%$ ethanol, which only has ethanol induced linear species, based on the ratio of backbone signals to end group signals is giving a $M_{\mathrm{n}}$ of approx. $5000 \mathrm{~g} \mathrm{~mol}^{-1}$ and therefore confirms the SEC results according to the literature [42, 43]. This type of calculation can only be performed when no cyclic molecules are present. In contrast to MALDI-MS traces of the methoxyethanol starting group can be found.
The sample with sodium carbonate shows a distinctly different NMR spectrum as most of the peaks are split apart, which is in accordance with the presence of low molecular mass oligomers [41] (see Fig. 9).

\section{Conclusion}

The influence of various compounds, which are considered possible impurities in the manufacture of L-lactide through biogenic processes, on the production of polylactic acid was investigated. Whereas glass transition temperature and melting point stay within rather narrow boundaries, molecular masses vary significantly. It could 
be shown that the process is very sensitive to some types of impurities, such as ethanol, which are in competition with methoxyethanol as polymerisation initiator. MALDI mass spectrometry clearly shows the incorporation of the new initiator and explains why higher amounts of these impurities lead to dramatically reduced molecular masses. The biggest difference was observed when sodium carbonate was present in higher concentrations. In this case a work up of the polymer was not possible in the conventional way and all analytical techniques employed showed that the molecular masses of the polymers decreased dramatically. Finally, it was demonstrated that molecular mass differences between SEC measurements and NMR calculations can be explained by the fact that the polymers produced under standard conditions are not strictly linear with methoxyethoxy starting groups but are a mixture of cyclic polymers and linear chains with various starting groups. Therefore, the ratio of starting group to repeat units derived from NMR experiments always leads to erroneous molecular mass values. For linear products the comparison is well suited. Further investigations into the influence of initiators on the tin (II)-2-ethylhexanoate catalysed L-lactide polymerisation will be carried out in order to better understand the formation process of the different polymer moieties.

Acknowledgements The NMR spectrometer was acquired in collaboration with the University of South Bohemia (CZ) with financial support from the European Union through the EFRE INTERREG IV ETC-AT-CZ programme (project M00146, "RERI-uasb").

The work was funded by European Regional Development Fund (EFRE) and the province of Upper Austria trough the program IWB 2014-2020 project BioRest.

The background picture for the graphical abstract was thankfully received from "freepik.com".

Funding Open access funding provided by Johannes Kepler University Linz.

\section{Compliance with ethical standards}

Conflict of interest The authors declare that they have no known competing financial interests of personal relationships that could have appeared to influence the work reported in this paper.

Open Access This article is licensed under a Creative Commons Attribution 4.0 International License, which permits use, sharing, adaptation, distribution and reproduction in any medium or format, as long as you give appropriate credit to the original author(s) and the source, provide a link to the Creative Commons licence, and indicate if changes were made. The images or other third party material in this article are included in the article's Creative Commons licence, unless indicated otherwise in a credit line to the material. If material is not included in the article's Creative Commons licence and your intended use is not permitted by statutory regulation or exceeds the permitted use, you will need to obtain permission directly from the copyright holder. To view a copy of this licence, visit http://creativecommons.org/licenses/by/4.0/.

\section{References}

1. Geyer R, Jambeck JR, Law KL (2017) Production, use, and fate of all plastics ever made. Sci Adv 3:e1700782. https://doi. org/10.1126/sciadv. 1700782

2. The global bio-based polymer market in 2019 - A revised view bioplastics MAGAZINE, 2020. https://www.bioplasticsmagazine. com/en/news/meldungen/20200127-The-global-bio-basedpolymer-market-in-2019-A-revised-view.php (Accessed 7 April 2020).

3. Bentley RW (2002) Oil Forecasts, Past and Present. Energy Explor Exploit 20:481-492

4. Laycock B, Nikolić M, Colwell JM, Gauthier E, Halley P, Bottle S, George G (2017) Lifetime prediction of biodegradable polymers. Prog Polym Sci 71:144-189. https://doi.org/10.1016/j. progpolymsci.2017.02.004

5. Babu RP, O'Connor K, Seeram R (2013) Current progress on bio-based polymers and their future trends. Prog Biomater 2:8. https://doi.org/10.1186/2194-0517-2-8

6. Kulkarni RK, Moore EG, Hegyeli AF, Leonard F (1971) Biodegradable poly(lactic acid) polymers. J Biomed Mater Res 5:169181. https://doi.org/10.1002/jbm.820050305

7. R. Griebel,Z. Smith, J.M. Merrick, Metabolism of Poly-beta-hydroxybutyrate. I. Purification, Composition, and Properties of native Poly-betahydroxybutyrate Granules from Bacillus megaterium, Biochemistry 7 (1968) 3676-3681. https://doi.org/10.1021/bi00850a047

8. Castro-Aguirre E, Iñiguez-Franco F, Samsudin H, Fang X, Auras $\mathrm{R}$ (2016) Poly(lactic acid)-Mass production, processing, industrial applications, and end of life. Adv Drug Deliv Rev 107:333-366. https://doi.org/10.1016/j.addr.2016.03.010

9. S. Fiori (Ed.), PLA Synthesis and Polymerization: Chapter 13. Industrial Uses of PLA, 2014

10. Gupta AP, Kumar V (2007) New emerging trends in synthetic biodegradable polymers - Polylactide: A critique. Eur Polymer J 43:4053-4074. https://doi.org/10.1016/j.eurpolymj.2007.06.045

11. European Bioplastics, Bioplastics market data 2018: Global production capacities of bioplastics 2018-2023, 2018.

12. E. Ten, L. Jiang, J. Zhang, M.P. Wolcott, Mechanical performance of polyhydroxyalkanoate (PHA)-based biocomposites, in: Biocomposites, Elsevier, 2015, pp. 39-52.

13. M. Ajioka, K. Enomoto, K. Suzuki, A. Yamaguchi, Basic Properties of Polylactic Acid Produced by the Direct Condensation Polymerization of Lactic Acid, Bulletin of the Chemical Society of Japan (1995) 2125-2131.

14. Kim KW, Woo SI (2002) Synthesis of High-Molecular-Weight Poly(L-Lactic acid) by Direct Polycondensation. Macromol Chem Phys 203:2245-2250

15. Nagahata R, Sano D, Suzuki H, Takeuchi K (2007) MicrowaveAssisted Single-Step Synthesis of Poly(lactic acid) by Direct Polycondensation of Lactic Acid. Macromol Rapid Commun 28:437-442. https://doi.org/10.1002/marc.200600715

16. Lu D-D, Yuan J-C, Lei Z-Q (2009) High molecular weight biodegraded poly(lactic acid-glycolic acid- $\varepsilon$-caprolactam) copolymer: direct polycondensation of lactic acid, glycolic acid and $\varepsilon$-caprolactam using $\mathrm{Sn}(\mathrm{II})$-organic anhydride as catalysts. Polym Adv Technol 20:536-540. https://doi.org/10.1002/pat.1378

17. Mahfoudh J, Salhi S, Delaite C, Abid S, El Gharbi R (2015) Random Poly(Lactic Acid-co- $\beta$-Alanine): Synthesis and Characterizations. Journal of Macromolecular Science, Part A 52:1002-1008. https://doi.org/10.1080/10601325.2015.1095603

18. Liu L, Chen XW, Wang P, Wei ZY, Liu CY, Qi M (2011) Synthesis, Microstructure and Properties of Poly(L-Lactic AcidCo- $\alpha$-Alanine) Obtained by Direct Melting Copolymerization. MSF 685:390-393. https://doi.org/10.4028/www.scientific.net/ MSF.685.390 
19. Kleine J, Kleine H-H (1959) Über hochmolekulare, insbesondere optisch aktive Polyester der Milchsäure, ein Beitrag zur Stereochemie makromolekularer Verbindungen. Die Makromolekulare Chemie 30:23-38. https://doi.org/10.1002/macp.1959.020300102

20. Fischer EW, Sterzel HJ, Wegner G (1973) Investigation of the structure of solution grown crystals of lactide copolymers by means of chemical reactions. Kolloid-Zeitschrift und Zeitschrift für Polymere 251:980-990. https://doi.org/10.1007/BF01498927

21. Myers M, Connor EF, Glauser T, Möck A, Nyce G, Hedrick JL (2002) Phosphines: Nucleophilic organic catalysts for the controlled ring-opening polymerization of lactides. J Polym Sci, Part A: Polym Chem 40:844-851. https://doi.org/10.1002/pola.1016

22. Lohmeijer BGG, Pratt RC, Leibfarth F, Logan JW, Long DA, Dove AP, Nederberg F, Choi J, Wade C, Waymouth RM, Hedrick JL (2006) Guanidine and Amidine Organocatalysts for Ring-Opening Polymerization of Cyclic Esters. Macromolecules 39:8574-8583. https://doi.org/10.1021/ma0619381

23. Leenslag JW, Pennings AJ (1987) Synthesis of high-molecular-weight poly(L-lactide) initiated with tin 2-ethylhexanoate. Die Makromolekulare Chemie 188:1809-1814. https://doi. org/10.1002/macp.1987.021880804

24. Shinno K, Miyamoto M, Kimura Y, Hirai Y, Yoshitome H (1997) Solid-State Postpolymerization of L-Lactide Promoted by Crystallization of Product Polymer: An Effective Method for Reduction of Remaining Monomer. Macromolecules 30:6438-6444. https:// doi.org/10.1021/ma9704323

25. Yu Y, Fischer EJ, Storti G, Morbidelli M (2014) Modeling of Molecular Weight Distribution in Ring-Opening Polymerization of L. L-Lactide, Industrial \& Engineering Chemistry Research 53:7333-7342. https://doi.org/10.1021/ie4028999

26. Sosnowski S, Lewinski P (2015) L-Lactide polymerization catalysed by tin(II) 2-ethyl-hexanoate. A deeper look at chain transfer reactions, Polymer Chemistry 6:6292-6296. https://doi. org/10.1039/C5PY00748H

27. Kricheldorf HR, Weidner SM (2019) About the influence of salicylic acid on tin(II)octanoate-catalyzed ring-opening polymerization of L-lactide. Eur Polymer J 119:37-44. https://doi. org/10.1016/j.eurpolymj.2019.07.003

28. Ryner M, Stridsberg K, Albertsson A-C, von Schenck H, Svensson M (2001) Mechanism of Ring-Opening Polymerization of 1,5-Dioxepan-2-one and L-Lactide with Stannous 2-Ethylhexanoate. A Theoretical Study, Macromolecules 34:3877-3881. https://doi.org/10.1021/ma002096n

29. Karidi K, Mantourlias T, Seretis A, Pladis P, Kiparissides C (2015) Synthesis of high molecular weight linear and branched polylactides: A comprehensive kinetic investigation. Eur Polymer J 72:114-128. https://doi.org/10.1016/j.eurpolymj.2015.09.011

30. Kricheldorf HR, Weidner SM, Meyer A (2020) High Tm poly(Llactide)s via REP or ROPPOC of L-lactide. Polymer Chemistry 11:2182-2193. https://doi.org/10.1039/C9PY01908A
31. Kricheldorf HR, Weidner SM, Scheliga F (2019) Ring-expansion polymerization (REP) of L-lactide with cyclic tin(II) bisphenoxides. Eur Polymer J 116:256-264. https://doi.org/10.1016/j. eurpolymj.2019.04.024

32. Joglekar HG, Rahman I, Babu S, Kulkarni BD, Joshi A (2006) Comparative assessment of downstream processing options for lactic acid. Sep Purif Technol 52:1-17. https://doi.org/10.1016/j. seppur.2006.03.015

33. van Wouwe P, Dusselier M, Vanleeuw E, Sels B (2016) Lactide Synthesis and Chirality Control for Polylactic acid Production. Chemsuschem 9:907-921. https://doi.org/10.1002/cssc.201501695

34. K. Oka, T. Matsuo, M. Kamikawa, N. Okamoto, T. Kondo (Hitachi Plant Technologies, Ltd. Tokyo) EP 2562263A1, 2013.

35. J. van Breugel, J. van Krieken, A. Cerda Baro, J.M. Vidal Lancis, M. Camprubi Vila (Purac Biochem B.V., Gorinchem) DE60014047T2, 2000.

36. Ghaffar T, Irshad M, Anwar Z, Aqil T, Zulifqar Z, Tariq A, Kamran M, Ehsan N, Mehmood S (2014) Recent trends in lactic acid biotechnology: A brief review on production to purification. Journal of Radiation Research and Applied Sciences 7:222-229. https://doi.org/10.1016/j.jrras.2014.03.002

37. Inskeep GC, Taylor GG, Breitzke WC (1952) Lactic Acid from Corn Sugar. Ind Eng Chem 44:1955-1966. https://doi. org/10.1021/ie50513a016

38. Milcent S, Carrère H (2001) Clarification of lactic acid fermentation broths. Sep Purif Technol 22-23:393-401. https://doi. org/10.1016/S1383-5866(00)00124-6

39. G.T. PECKHAM, The Commercial Manufacture of Lactic Acid, Chemical \& Engineering News 22 (1944) 440-443,469.

40. Gracia-Fernández CA, Gómez-Barreiro S, López-Beceiro J, Naya S, Artiaga R (2012) New approach to the double melting peak of poly(L-lactic acid) observed by DSC. J Mater Res 27:1379-1382. https://doi.org/10.1557/jmr.2012.57

41. Espartero JL, Rashkov I, Li SM, Manolova N, Vert M (1996) NMR Analysis of Low Molecular Weight Poly(lactic acid)s. Macromolecules 29:3535-3539. https://doi.org/10.1021/ma950529u

42. Kowalski A, Duda A, Penczek S (1998) Polymerization of L. L -Lactide Initiated by Aluminum Isopropoxide Trimer or Tetramer, Macromolecules 31:2114-2122. https://doi.org/10.1021/ma971737k

43. Jalabert M, Fraschini C, Prud'homme RE (2007) Synthesis and Characterization of Poly(L-lactide)s and Poly(D-lactide)s of Controlled Molecular Weight. J Polym Sci A Polym Chem 45:19441955. https://doi.org/10.1002/pola.21960

Publisher's Note Springer Nature remains neutral with regard to jurisdictional claims in published maps and institutional affiliations. 